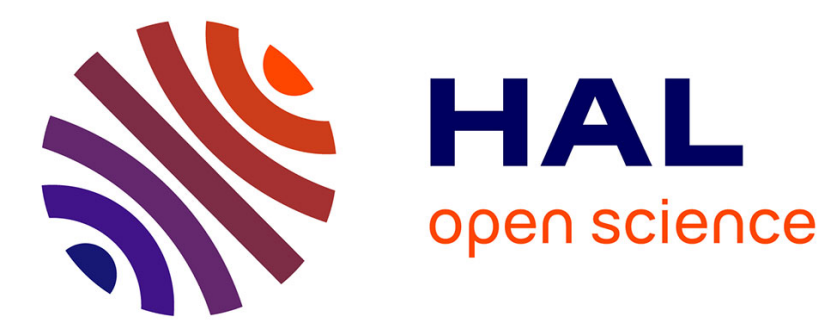

\title{
Using night TIR images to model the gap fraction of a dense maize canopy
}

Xing Fa Gu, Jean-François Hanocq, M. Weiss, Tao Yu, Guoliang Tian, Roland Bosseno, Michel Legrand

\section{- To cite this version:}

Xing Fa Gu, Jean-François Hanocq, M. Weiss, Tao Yu, Guoliang Tian, et al.. Using night TIR images to model the gap fraction of a dense maize canopy. IEEE international geoscience and remote sensing symposium, Jul 2003, Toulouse, France. 10.1109/IGARSS.2003.1295538 . hal-02763760

\section{HAL Id: hal-02763760 \\ https://hal.inrae.fr/hal-02763760}

Submitted on 11 Aug 2021

HAL is a multi-disciplinary open access archive for the deposit and dissemination of scientific research documents, whether they are published or not. The documents may come from teaching and research institutions in France or abroad, or from public or private research centers.
L'archive ouverte pluridisciplinaire HAL, est destinée au dépôt et à la diffusion de documents scientifiques de niveau recherche, publiés ou non, émanant des établissements d'enseignement et de recherche français ou étrangers, des laboratoires publics ou privés.

\section{(c)(1)}

Distributed under a Creative Commons Attribution| 4.0 International License 


\section{Using night TIR images to model the gap fraction of a dense maize canopy}

\author{
Xingfa GU, Jean-Francois HANOCQ Marie WEISS \\ CSE-INRA, Avignon, France \\ e-mail: gu@avignon.inra.fr
}

Roland BOSSENO

IRD / CSE-INRA, Avignon, France

e-mail: rbosseno@avignon.inra.fr

\author{
Tao YU, Guoliang TIAN \\ LARSIS-IRSA-CAS, Beijing, China \\ e-mail: yutao@irsa.irsa.ac.cn
}

\author{
Michel LEGRAND \\ Université des Sciences et Technologies de Lille \\ e-mail: legrand@loa.univ-lille1.fr
}

\begin{abstract}
In order to estimate directional variation of gap fraction over a high dense maize canopy, a geometric optical and radiative transfer (GORT) model was improved to simulate the hemispherical gap fraction, the model was validated by a crane borne experiment using a narrow FOV thermal infrared camera conducted at night. The research revealed that the path length is a function of canopy geometrical structure, view direction and position, which leads to the row effect on hemispherical gap fraction: azimuthal variation of gap fraction is insignificant except for the observations parallel to the rows. For dense canopies, the value of gap fraction declined quickly in small view zenith rather than in large view zenith range, which leads the curves to show a concave shape. The experiment was conducted at $22 \mathrm{~h}$ local time on July 26 in 1999 (LAI=5) for the validation. At the time, brightness temperatures of leaves and soil had Gaussian distribution, their mean values presented a significant difference $\left(24.3^{\circ} \mathrm{C}\right.$ and $\left.26.5^{\circ} \mathrm{C}\right)$ comparing to their small standard deviations $\left(0.52^{\circ} \mathrm{C}\right.$ and $\left.0.44^{\circ} \mathrm{C}\right)$, gap fraction could be discriminated from canopy background. Observations showed that most gaps appeared between the adjacent rows, which lead the high dense canopy still to keep row feature in thermal infrared images. As conclusion of the comparison, the model could capture the main features of the measured gap fraction. With a proper adjustment of input leaf optical parameters, the simulated gap fraction showed a fairly good agreement with observed gap fraction.
\end{abstract}

Keywords-component; gap fraction; night thermal infrared images;maize canopy;GORT

\section{INTRODUCTION}

Gap fraction is the probability that a ray penetrates through the canopy unintercepted by the leaves and stems [1]. As a key variable describing canopy architecture and biomass spatial distribution, it has played an important role in modeling the response of canopies to visible, infrared, and microwave radiation, and has been widely used in many remote sensing applications [1, 2]. For an ideal homogeneous canopy, gap fraction is well described by leaf area index (LAI) and leaf inclinations [3]. However, in the case of real canopies, especially row crops with a marked heterogeneous biomass distribution, differences appeared between measured and

This study is supported by INRA France and China's Funds (Grant No. 2000077902, 2002AA130010-2, and CX020011) model predicted gap fraction. The methodologies used to acquire and analyze hemispherical gap fraction have been well described in a vast of papers. Most of the measurement were based on reflectance of solar radiation in visible bands, the accuracy is affected by the target spectral characteristics, sky condition and measurement geometry. With the development of thermal infrared remote sensing technologies, thermal infrared images with high geometric and radiometric accuracy have been widely used in the remote sensing applications. Until now, few researches on gap fraction measurements using emitted thermal radiation have been reported, which would provide another approach in gap fraction research.

The objective of this research is to investigate the spatial distribution and the directional variation of gap fraction over the whole hemisphere for a full covered maize canopy. The geometrical description of the model is following the researches of Ganis [4]. In the measurement of canopy gap fraction, different from the methods usually available in day time, we observed the canopy using a TIR camera at night, and discriminated soil background from leaves by their brightness temperature difference.

\section{THE GAP FRACTION EXPRESSION FOR A MAIZE CANOPY}

Supposing the row structure is still kept even in dense conditions, we adopt the geometric structure presented by Jackson et al. [5] that maize field was classified into two parts: extended rectangle hedgerow and space area between adjacent hedgerows to capture this row feature. The hedgerows are porous so that a light beam could penetrate through their gaps; furthermore, the vegetation rectangles are not directly lying on the soil surface, they are shifted over the soil plane with a limit distance [4]. We assume that the stem part and small leaves between the soil plane and the bottom of vegetation rectangles are neglected. This simplification is acceptable when most of biomass concentrates in the upper part.

Gap fraction of a homogeneous canopy layer depends therefore on the path length through the canopy, and this expression could be applied over a row structure canopy whose $l(\theta)$ and $D$ vary with spatial position. If the clumping parameter 
$\lambda(\theta)$ and the projection function $G(\theta)$ depend only on view zenith $\theta$ and not on view azimuth $\varphi$ as addressed by Baret et al. [6], gap fraction $P(\theta, \varphi, x, y)$ in direction $(\theta, \varphi)$ at position $(\mathrm{x}, \mathrm{y})$ for a given row structure canopy is expressed as follows:

$$
P(\theta, \varphi, x, y)=\exp (-\lambda(\theta) G(\theta) D l(\theta, \varphi, x, y))
$$

where $l(\theta, \varphi, x, y)$ is the effective path length that only accounts for the beam passing through the canopy, the length passing through the adjacent spacing between the rows is neglected; $D$ here is the effective leaf area density, equals to $\frac{L A I W}{a b}$. In the simulation, The projection function $G$ is given by Campbell [7], The clumping parameter $\lambda$ for the simulation of the model is a spline line fitting the curve presented by Espana et al. [8].

The canopy gap fraction $P(\theta, \varphi)$ is obtained by integrating the elemental values over the whole area:

$$
P(\theta, \varphi)=\frac{\iint_{S} P(\theta, \varphi, x, y) d x d y}{S}
$$

\section{THE MEASUREMENT OF GAP FRACTION OVER THE MAIZE CANOPY}

\section{A. Camera-crane system and canopy brightness temperature} measurements

The acquisition of TIR images was conducted by a cameracrane system, which consists of a one-band TIR camera, an industrial crane and a multidirectional platform. The TIR camera was INFRAMETRICS Model 760 equipped with $7^{\circ} \times 5^{\circ}$ lens. The spectral window of the camera is $7.25 \mu \mathrm{m}$ to $13.25 \mu \mathrm{m}$. Jacob (1999) and Lagouarde et al (2000) investigated the error sources and provided an optimised calibration method, which improves the accuracy up to $\pm 0.5^{\circ} \mathrm{C}$ with $95 \%$ confidence interval for a single measurement.

Before the measurement, the crane was moved to the middle of field, and the crane boom was set perpendicular to the rows. The TIR camera scanned the field along three stripes: along the row (north-nadir-south,), cross the row (east-nadirwest), and a slope one (north east-nadir-south west). During the scanning, imaging process lasted 20 seconds with a rate of one image per second. Therefore there are about 20 images for one area, the averaged brightness temperature is used as true value of an area's brightness temperature to improve the measurement accuracy so that the actual confidence interval $\underline{2 \sigma}$

$(\overline{\sqrt{n}})$ becomes $0.22^{\circ} \mathrm{C}$, where $\sigma$ is standard deviation, $\mathrm{n}$ is the number of the measurements. Scanning one stripe usually needed 5 minutes.

\section{B. The maize canopy}

The experimental field is located at INRA-Avignon (435' $\mathrm{N}$ latitude, $4^{\circ} 5^{\prime} \mathrm{E}$ longitude) in the South of France, its size is 150 meters long in North-South, 100 meters width in
East-West direction. The maize was planted north-south oriented on May 10, 1999. Row spacing was $0.8 \mathrm{~m}$, plant density was 9.32 plant per $\mathrm{m}^{2}$.

TABLE I. AGRONOMIC AND GEOMETRICAL PARAMETERS OF THE CANOPY ON JULY 26, 1999

\begin{tabular}{|c|c|c|c|c|}
\hline$L A I$ & $H(\mathrm{~m})$ & $h(\mathrm{~m})$ & $w(\mathrm{~m})$ & $A(\mathrm{~m})$ \\
\hline $5 \pm 0.3$ & $1.85 \pm 0.17$ & $0.5 \pm 0.1$ & $0.92 \pm 0.07$ & $0.88 \pm 0.08$ \\
\hline
\end{tabular}

The geometrical parameters of the maize canopy were collected at day time on July 261999 using a digital camera which was mounted on the crane. Leaf area index was measured by using a destructive method. Table 1 shows measured agronomic and geometrical parameters of the canopy. LAI is the averaged leaf area index; $\mathrm{H}$ is plant averaged height; $h$ is the averaged height of the plant bottom leaf, wilt and small leaves near the root area are neglected, we suppose that canopy biomass is mainly distributed between $H$ and $h ; w$ is the plant averaged width defined as the maximum length viewing the plant at the nadir. Normalised width of plant rows is defined by the equation:

$$
A=w \sum f_{\alpha} \cos \alpha
$$

where $\alpha$ is plant averaged azimuth, it is defined as the angle between plant orientation and the cross row direction, plant orientation is the direction to which large leaves direct; $f_{\alpha}$ is the frequency of angle $\alpha$ appeared in the measurement, the averaged plant azimuth angle is about $12^{\circ}$. In the measurement, the parameters were collected from 25 samples.

\section{RESULTS AND DISCUSSION}

\section{A. Model prediction}

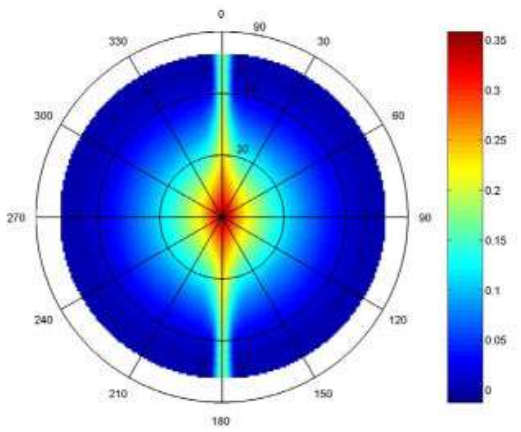

Figure 1. Polar map of gap fraction distribution

A polar map of hemispherical gap fraction distribution is shown in Figure 1. The maximum value appears in the nadir view with a value about 0.35 , it declines with the increase of zenith angle in all azimuth directions. Along the row direction (azimuth $=0^{\circ}$ and $180^{\circ}$ ), gap fraction decreases slowly, its value approaches the limit value of $0.16\left(=\frac{L-a}{L}\right)$ for a very large zenith angle. Near the row direction, there exists a narrow 
range where gap fraction keeps a large value at large zenith angle. This may be related to the effect of space area between two adjacent plant arrays: when the space area is obscured because of the change in view direction, the value of gap fraction declines sharply. For other azimuth direction, gap fraction drops quickly to zero in a similar way. This simulation represents well the main feature of gap fraction for a row canopy, and is in good agreement with those already reported in the literature as mentioned before.

\section{B. Measurement of gap fraction using TIR camera at night}

To illustrate the spatial distribution of the canopy architecture, Figure 2 shows a thermal infrared image captured by the TIR camera in the nadir view at $22 \mathrm{~h}$ local time on July 26,1999 . It is reasonable to suppose that the temperature distribution of each component follows a normal law. To extract the desired statistical parameters such as mean value and range of component brightness temperature, least squares fitting of peak shapes were used to fit the histogram of the images. Two fitted Gauss functions for soil and vegetation are iteratively adjusted until the difference between the actual and calculated data is minimized. Once the iterative minimum is researched, the area of each Gaussian function is the most probable estimates of component fraction, and the statistical parameters are determined. Vegetation and soil mean brightness temperatures were around $24.3^{\circ} \mathrm{C}$ and $26.5^{\circ} \mathrm{C}$, their standard deviation are $0.15,0.52^{\circ} \mathrm{C}$ and $0.44^{\circ} \mathrm{C}$ respectively.

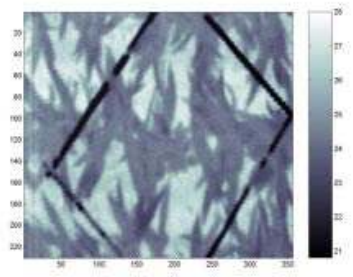

Figure 2. One thermal infrared image (a) captured in nadir at $22 \mathrm{~h}$ local time on July 26, 1999.

\section{Validation of the model using measured gap fraction}

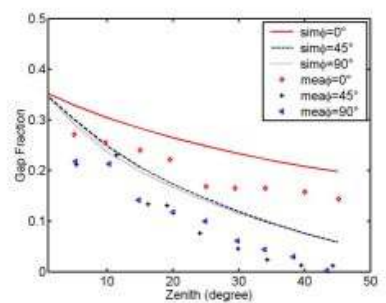

Figure 3. The comparison of simulated and measured gap fraction in 3 directions that the azimuth are $0^{\circ}, 45^{\circ}$ and $90^{\circ}$ respectively.

The model outputs were compared with the measurement data. Figure 3 shows the simulated and measured gap fraction. Within the view range from the nadir to $45^{\circ}$, angular variations of measured gap fraction along and cross the row are 0.15 and 0.3 , the curves show concave shapes. Correspondingly, the calculated gap fractions have the similar value ranges and curve trends but a shift about 0.05 . This is confirmed by the analysis presented in Figure 15 that the agreement index $\left(\mathrm{R}^{2}\right)$ is 0.99 , the slope has no significant difference from 1 , root mean square error (RMSE) is only 0.002 , however, the shift is 0.06 .

\section{SUMMARY AND CONCLUSIONS}

To illustrate directional variation of maize gap fraction, a simple hybrid geometric optical and radiative transfer approach has been presented to simulate the effect of maize canopy structure. Although a series of simplifications was made in the description of maize canopy geometrical structure and optical properties, the model captured the main features of the measured gap fraction of a maize canopy. The results show that the variation of path length over the canopy depends both on zenith and azimuth angle, its variation leads to the row features of hemispherical gap fraction.

A methodology based on the use of thermal infrared images captured by narrow FOV TIR camera at night was developed to measure the directional variation of canopy gap fraction. The relationship between gap fraction and view zenith and azimuth over a dense maize canopy was investigated, then a geometric optical and radiative transfer model was proposed and improved for estimating the gap fraction within row canopies. Observations of maize canopy on July 26, 1999 showed the directional variation of gap fraction of a high dense maize canopy and the spatial distribution of maize leaves. The measured gap fraction confirmed the results provided by many researchers that very little azimuthal variation appears for gap fraction except for the observations parallel to the row: along row direction, gap fraction declines from the nadir slowly, in other azimuth, gap fraction declines sharply, this difference was significant in their comparison, which reflects the essential of row structure of maize canopy.

\section{REFERENCES}

[1] J. Warren Wilson, "Stand structure and light penetration. 1-Analysis by points quadrates", Journal of applied Ecology, 2: 383-390. , 1965.

[2] Weiss, M. "Hemispherical reflectance and albedo estimate from the accumulation of across - track sun-synchronous satellite data". Journal of Geophysical Research, 104: 22221-22232, 1999.

[3] J. Ross, "Radiative transfer in plant communities" Vegetation and the Atmosphere, 1: 13-52. 1975

[4] A. Ganis, "Radiation transfer estimate in a row canopy: a simple procedure". Agricultural and forest meteorology, 88: 67-76, 1997.

[5] J.E. Jackson and J.W. Palmer, "A simple model of light transmission and interception by discontinuous canopies". Annual of Botany, 44: 381383. 1979.

[6] B..Andrieu and H. Sinoquet., "Evaluation of structure description requirements for predicting gap fraction of vegetation canopies". Agricultural and Forest Meteorology, 1993: 207-227

[7] G.S. Campbell, "Extinction coefficients for radiation in plant canopies calculated using an ellipsoidal inclination angle distribution." Agricultural and Forest Meteorology, 36: 317-321. 1986.

[8] M.L. Espana Boquera, "Simulation de la variation temporelle, directionnelle et spectrale de la réflectance de cultures de maïs à partir d'un modèle dynamique de la structure 3D du couvert", Thèse, Université de Marne-la-Vallée. 1997. 